Editorial

\title{
The 2018 Conference of the International Sports Engineering Association ${ }^{+}$
}

\author{
Hugo G. Espinosa *, David R. Rowlands, Jonathan Shepherd and David V. Thiel \\ Griffith School of Engineering and Built Environment, Griffith University, Brisbane, Nathan QLD 4111, \\ Australia; d.rowlands@griffith.edu.au (D.R.R.); j.shepherd@griffith.edu.au (J.S.); \\ d.thiel@griffith.edu.au (D.V.T.) \\ * Correspondence: h.espinosa@griffith.edu.au \\ + Presented at the 12th Conference of the International Sports Engineering Association, Brisbane, \\ Queensland, Australia, 26-29 March 2018.
}

Published: 12 February 2018

Every second year, the International Sports Engineering Association (ISEA) conducts a conference somewhere around the world. In 2018, for the first time in 18 years, the conference was held in the Southern Hemisphere in Brisbane, Queensland, Australia. Following the ISEA2016 meeting in Delft, Holland, there is no doubt that a two year period results in remarkable changes in sporting research and technology and the 2018 meeting brought together over 250 world leading experts in the field of sports engineering to present their latest research results, the latest research directions and to interact with commercial organisations who introduce the latest technologies in the market place.

Sports Engineering is a relatively new engineering discipline combining the fields of mechanical engineering, electronic and communications engineering, computational modelling and data analytics as well as biomechanics and sensors.

The Brisbane conference had keynote speakers in the field of garments, wearables, footwear technology, modelling and optimisation software and the latest world-wide standards in everything from ball composition to line prediction algorithms. This collection of more than 140 papers have been extensively reviewed by world leaders in the technology, revised and then re-reviewed to ensure compliance and excellence. They have been categorised into specific sport and research oriented disciplines although many papers straddle these boundaries.

As editors of this volume, we are delighted to present the conference outcomes, to acknowledge the many paper reviewers from around the world, and to thank the conference participants for creating such an exciting and cooperative environment to share this new knowledge.

(c) 2018 by the authors; Licensee MDPI, Basel, Switzerland. This article is an open access article distributed under the terms and conditions of the Creative Commons Attribution (CC BY) license (http://creativecommons.org/licenses/by/4.0/). 